\title{
An Alternative System for Eccentrically Braced Frames Resisting Lateral Loads
}

\author{
Nagui William Bishay-Girges \\ Department of Civil Engineering \\ College of Engineering, University of Hail \\ Hail, Saudi Arabia \\ n.bishay@uoh.edu.sa
}

\begin{abstract}
Eccentrically braced steel frames are structures used to resist lateral loads as they combine the ductility that is characteristic of moment frames and the stiffness associated with braced frames. Damper devices can be used as the main source of energy dissipation and have become more popular lately for the lateral control of structures. Control devices generally reduce damage by increasing structural safety, serviceability and preventing the building from collapse during vibration. This study focused on improving the performance of the structures with a proposed damping system, which has more advantages than eccentrically braced frames (EBFs). It can accommodate many architectural features and make construction and complementarity in the structures easier. The purpose of this study is to evaluate the performance of the structure with the proposed damping system and its construction in the building.
\end{abstract}

Keywords-lateral forces; eccentrically braced frames; active link; collector beam; dampers

\section{INTRODUCTION}

Eccentrically braced frames (EBFs) are a lateral loadresistance system that can be considered a hybrid between conventional moment-resisting frames (MRFs) and concentrically braced frames (CBFs). EBFs have become an attractive lateral resistance structural system since they provide high levels of both elastic stiffness and ductility. The distinguishing characteristics of an EBF are that at least one of the braces is connected in such a way that the brace force is transmitted either to another brace or to a column through shear and bending in a beam segment.
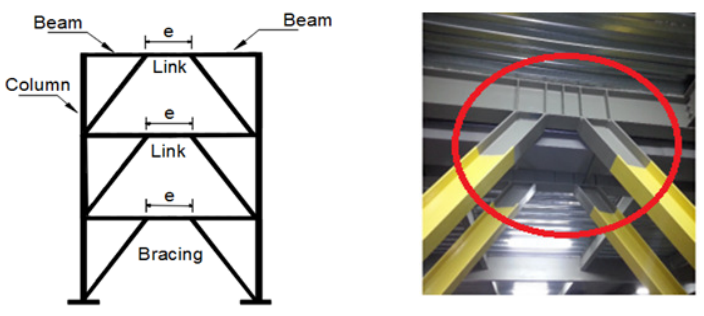

Fig. 1. Eccentrically braced frame

The short segment of the frame generally designated by the length (e) is called link as shown in Figure 1. In EBF systems, yielding is concentrated only at link segments and all other members of the frame (beams, columns and braces) are expected to behave elastically. Therefore, links can be considered as structural fuses which will dissipate the lateral input energy through stable and controlled plastic deformations. It is evident that the ability to dissipate energy depends strictly on the plastic deformations essentially located in links, designed to plasticize before beams, braces and columns, designed to use the forces generated by yielded and hardened links in order to remain in the elastic field. The eccentric-braced frame, as a system, has features for resisting lateral forces:

- The system can be designed for stiffness, or drift control.

- The link beam is designed to yield in shear or flexure prior to initiation of buckling or yielding of bracing member.

- Yielding of the link beam is a ductile phenomenon that absorbs energy and reduces the dynamic structural response by increasing the damping and the natural period of the building.

\section{ENERGY DISSIPATION MECHANISM}

In the design of a lateral resistant EBF, energy dissipation mechanism (also commonly called collapse mechanism), is constructed by assuming rigid plastic behavior of the members (Figure 2). In Figure $2 \theta$ represents the overall frame drift. The links are cross-hatched to indicate they have yielded in shear and have formed a shear hinge. For the EBFs the rotation demand on the links is much larger than $\theta$ and from the geometry of the mechanism, it can be determined as follows:

$$
\gamma=\frac{L}{e} \theta
$$

Link rotation, particularly for short links, is typically denoted by the symbol $\gamma$ as a reminder of the importance of shear yielding in supplying link rotation. The relation between frame drift $\theta$ and link rotation $\gamma$ depends on the configuration of the EBF and must be determined from the appropriate mechanism. One of the most significant collapse criteria for EBFs was obviously the failure of link elements due to the over passing of the plastic rotation limit. 


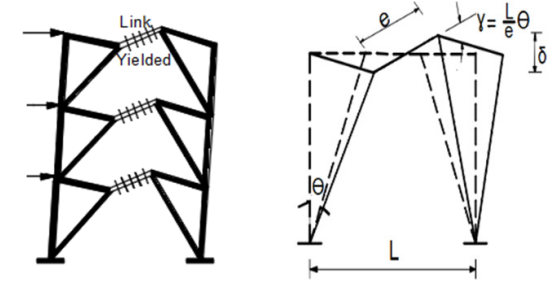

Fig. 2. Energy dissipate in plastic mechanisms

The plastic rotation is defined as the ratio between the relative vertical displacement $\delta$ and the length e:

$$
\frac{v_{1}-v_{2}}{e}=\frac{\delta}{e}=\gamma_{\text {link }}
$$

where $v_{1}$ and $v_{2}$ are the vertical displacements in the ends of the links.

\section{CHARACTERISTICS OF LINKS}

The length of a link segment $e$ is one of the key parameters controlling stiffness, strength ductility, and overall behavior of an EBF system. The link length ratio $\rho=e /\left(M_{p} / V_{p}\right)$, where $M_{p}$ and $V_{p}$ are the plastic moment and plastic shear capacities of the link, provides a convenient measure for the yield behavior. The theoretical limit between the behavior dominated by shear and flexure is based on simple plastic theory. For a link in equilibrium (Figure 3), shear and flexural yielding occur simultaneously. From statics, the length ratio for theoretical balanced failure is 2.0. For $\rho<2.0$, the link will reach full plastic shear capacity before full plastic moment capacity and, therefore, yield in shear, and vice versa. However, links do not behave as the plastic theory suggests. Links experience marginal interaction between shear and moment with and without axial loading, but strain hardening has significant effects. For that reason, there is a range of length ratios in which failure behavior changes from shear to flexural yielding for increasing length ratios. Forces acting on an isolated link, and the relationship between shear and bending moment in the link based on static equilibrium are illustrated in Figure 3. When $M_{a}=M_{b}=M$ the equation reduces to $V \cdot e=2 M$.

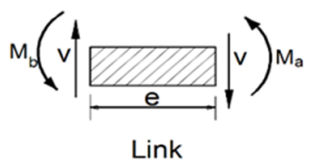

Fig. 3. Static equilibrium of link element.

For this case, if one considers simple plastic theory, i.e. no strain hardening and no $\mathrm{M}-\mathrm{V}$ interaction, it is simple to derive that a link of length $e=2 M_{p} / V_{p}$ is the theoretical dividing line between a link that yields in shear and one that yields in bending moment. In this equation, $M_{p}=Z F_{y}$ is the fully plastic moment of the section and is the fully plastic shear capacity of the section.

$$
V_{p}=0.55 F_{y} \cdot d . t_{w}
$$

where $F_{y}$ is the yield strength of the steel, $Z$ the plastic modulus, $\mathrm{d}$ is the beam depth, and $t_{w}$ is the web thickness.
Thus, based on simple plastic theory, if $\mathrm{e}<2 M_{p} / V_{p}$, the link shear will reach $V_{p}$ before the end moments reach $M_{p}$, and the link will yield in shear. In order to assure more desirable behavior of that yield in shear, it is recommended that the link length comply with:

$$
e \leq 1.6 \frac{M_{p}}{V_{p}}
$$

Both top and bottom flanges of the active link must be prevented from laterally deflecting. The active links are not usually long enough to require resistance between supports, however lateral restraint at the supports is always required. The strength requirement that must be met by the restraints is $1.5 \%$ of the beam flange design capacity. The beam adjacent to the active link region has normally the same section size with the active link itself and must be designed for the capacity derived actions induced in the beam by yielding of the active link. The collector beams are subjected to high axial forces and bending moments and must be designed as beam-columns for combined actions. The design shear force is unlikely to be significant, and therefore no shear and bending interaction should be considered. The collector beam top and bottom flanges must be laterally braced at the ends of the active link. The position of maximum bending moment (yielding region) in the collector beam is always adjacent to the end of the active link region, so the lateral bracing provided for the active link provides a lateral brace for the collector beam yielding region. The length of the collector beam between the active link region and the column must be able to resist the design compression force $N$. The top flange of the collector beam is usually effectively connected to a concrete slab (e.g. with shear welded shear studs) in such a way that it restraints the beam against axial shortening and also laterally supports the top flange.

\section{SIZE OF ACTIVE LINKS}

Steel links are subjected to high levels of shear forces and bending moments in the active link regions. The link is a single continuous member, the beam segments outside the link must be designed for the maximum possible forces that can be developed in the link. Consequently, oversized links are often designed, something that causes the other members and connections of the EBF to be proportionally large, increasing the overall cost of the structure. For most EBF configurations, the shear force in the active link $V_{\text {link,i }}$ (at level $i$ ), can be related to the story shear force in the level above the link (level $i+1)$ :

$$
V_{\text {link }, i}=V_{i+1} \frac{h_{s}}{L}
$$

where $V_{i+1}$ is the story shear force at level $i+1, h_{s}$ the inter story height for story $i$, and $\mathrm{L}$ is the EBF bay width (spacing between column center lines). In eccentrically braced frames, the vertical force components in the diagonal braces are transferred to the columns or the braces through shear and bending in the beams. In a sense, this makes eccentrically braced frames a compromise between a truss and a moment resisting frame. The truss-like characteristics endow the frame with high stiffness while the moment resisting frame-like characteristics provide the frame with large ductility capability. 

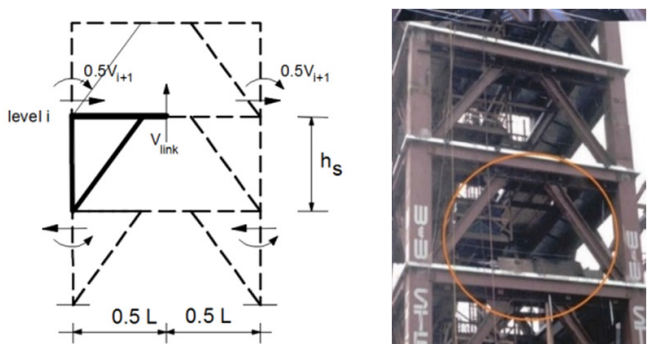

Fig. 4. Collector beam and stiffener.

\section{REPLACEABLE LINKS}

The repair of the link after a lateral damage event is difficult and costly. Figure 5, shows the replacement of the EBF links which is a good solution for reducing overall costs in both initial construction and repair stages.

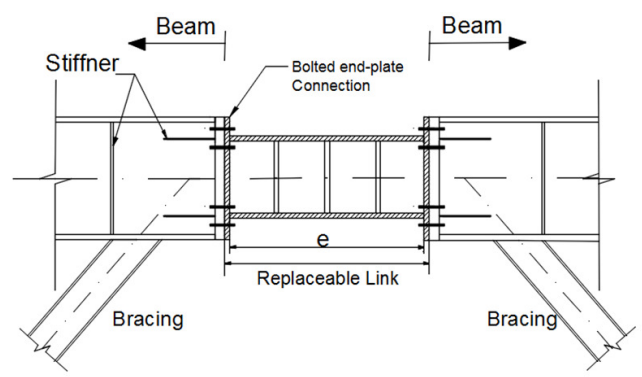

Fig. 5. Replaceable link in EBF

\section{SUPPLEMENTARY DAMPING TO STRUCTURES}

Structural control is an alternative energy dissipation approach that can be achieved by supplementary damping systems. Adding damping is controlling the structural deformation by using damper devices. Supplemental damping by increasing the system damping primarily reduces the inertia loads induced in the structural system. This effect may provide:

- Increased protection of the structural system since member loads are reduced.

- A reduction in inelastic deformation sustained by the structure since some of the input energy is dissipated.

- A reduction in non-structural damage since the maximum response of the structure is reduced.

Many buildings constructed after the earthquakes in New Zealand were built using a structural control system. An example is the Opus House in Christchurch which features fluid viscous dampers in conjunction with steel moment frames. The dampers are installed on the bracing system at each side of the building and are distributed through the height of the building. Another example is a 14-level office building constructed in Wellington in 2017. The modern design implements the international best practices in safety and resilience with base isolation and a diagrid structure. The idea of diagrid structure appears to be close to the proposed system adopted in this research. Control of the structure response under lateral forces has been demonstrated in [21] using a passive control system. Friction dampers are a typical representative of passive control systems, which are used to dissipate the input energy through solid friction. The passive control system operates without requiring an external power source, which is necessary for active and semi-active control systems. The study showed that a large amount of the total input energy was dissipated by friction dampers. Authors in [22] compared the performance of steel frames with concentric steel bracing reinforced with improved frictional dampers and steel frames with concentric steel bracing without dampers. They showed that in the absence of dampers, the energy they would absorb may damage parts of the structure.

\section{PROPOSED DAMPING SYSTEM}

The proposed system can be used as an alternative to the EBF. It is based on the use of a damper attached to longitudinal bracing throughout the structure to produce the damping forces and transfer them to different levels of the structure as shown in Figure 6. The proposed system has an advantage over EBFs. It can accommodate various architectural features and provides room for doors, windows and hallways allowing access through the frames while the braces in the typical eccentric configurations get in the way of such features.

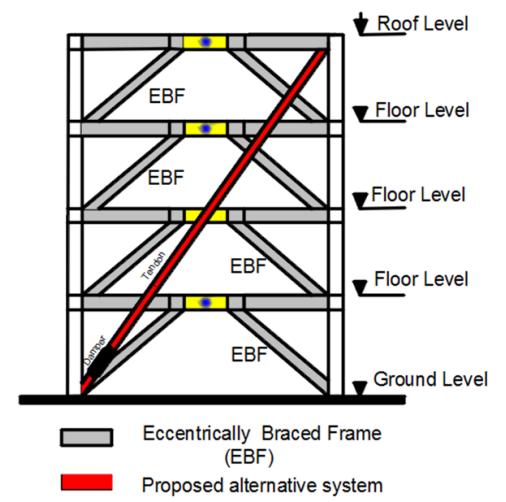

Fig. 6. Proposed alternative system for EBF.

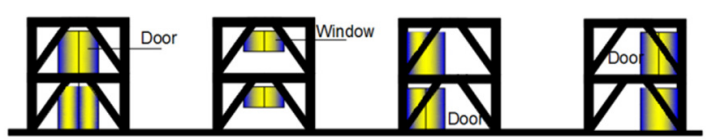

Fig. 7. EBF gets in the way of various architectural features

One benefit of using the damping-tendon system is that there is considerable flexibility regarding the placement of EBFs, resulting in less interference with the architectural features of the building. Figure 8 shows the architectural benefits of the proposed system as compared to the typical EBF systems.

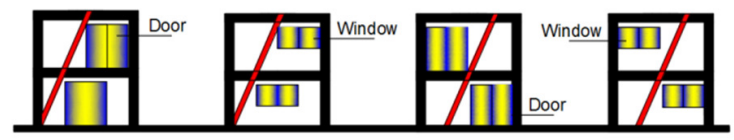

Fig. 8. Architectural features with the proposed system 


\section{INSTALLING THE DAMPING SYSTEM}

The present study provides an alternative and potentially more economical solution that is based on the principles of passive control. The proposed lateral approach intends to protect structures by introducing a tendon system with an energy dissipation device at the end of the tendon. The proposed system can be used as a good alternative solution for EBF for lateral load resistance. It consists of a damper device installed at the ground load of the structure. Supplementary dampers at the ground floor of the structure transfer the control forces provided by the devices through the rest of the structure using straight tendons that significantly reduce and control the response of the structure when exited by lateral forces. The main feature of the concept is using only one damper on one side or two dampers, one on each side of the structure, to produce the control forces needed, and transfer them to the rest of the building by using the tendon as shown in Figure 11. With the damper-tendon system, it is not necessary to distribute dampers throughout the height of the structure. The damper device that is adopted in this research consists of ring spring dampers. Ring springs are passive devices with no reliance on external energy sources. With ring-spring dampers, no maintenance is required, nor leakage can occur because they are constructed of steel. Ring-spring dampers have a small length and diameter when compared to other types of dampers such as viscous fluid dampers. As shown in Figure 9, damping forces are applied to the structures by the dampers placed at the lower end of the tendon (at ground floor). The damping forces have a horizontal component that must be resisted by the reinforced concrete slab action at the floor level. The damper is installed to the steel column using steel plates and is connected to the tendon on the other end. The connection between the damper and the diagonal tendon can be done by using welded steel plates connected to the damper by steel bolts. The tendon is fixed in the concrete slab at the floor level using four steel plates installed in the concrete slab using anchor bolts (Figure $10)$.

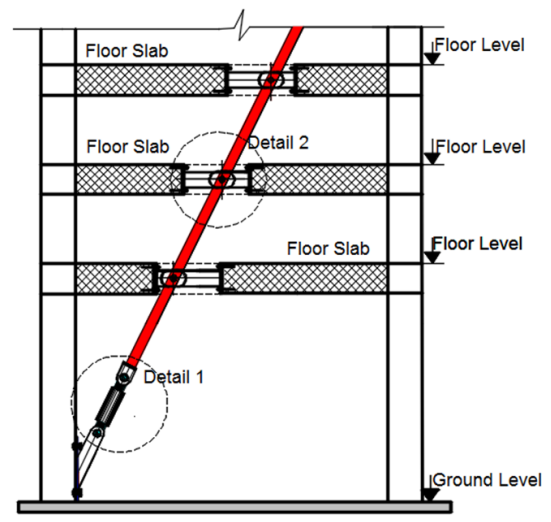

Fig. 9. The proposed system is installed to the ground floor and connected to floor slabs.

\section{EFFECT OF THE PROPOSED SYSTEM IN REDUCING THE STRUCTURES' RESPONSE}

To illustrate the effect of the proposed damping system in controlling the impact of lateral forces on structures, a nine story building was used. A sketch of a building's typical floor is shown in Figure 11. The spacings between grids are $8 \mathrm{~m}$ and $5 \mathrm{~m}$ in $\mathrm{x}$ and $\mathrm{y}$ direction respectively.

(a)

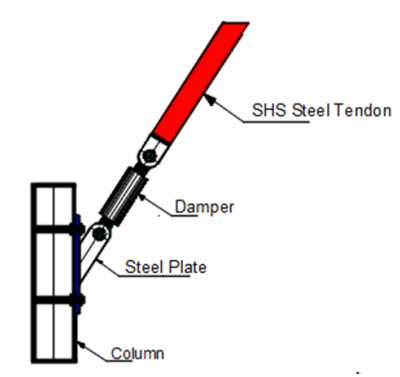

(b)

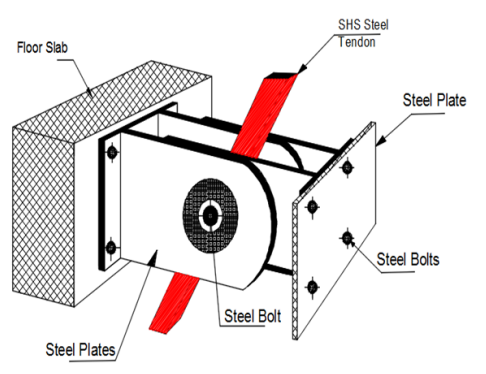

Fig. 10. Connection of the tendon at (a) ground and (b) floor level

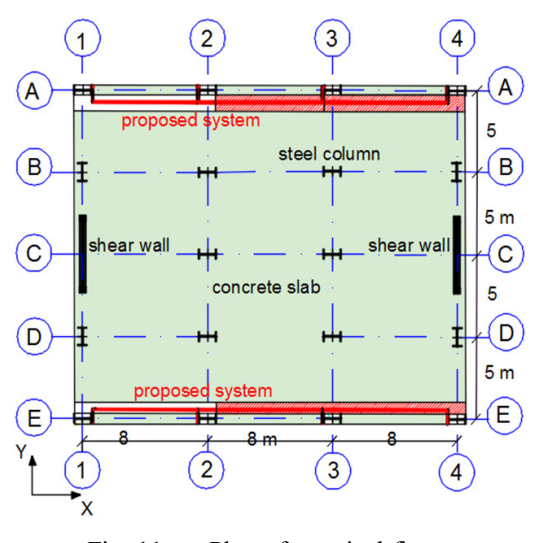

Fig. 11. Plan of a typical floor

The total area of each floor is $24 \mathrm{~m} \times 25 \mathrm{~m}$ and its height is $3.5 \mathrm{~m}$ for the whole building. The dead load is estimated to be $5.0 \mathrm{kN} / \mathrm{m}^{2}$ and the live load of $2.0 \mathrm{kN} / \mathrm{m}^{2}$ is used assuming that the structure is a residential building. The load combination case is the ultimate dead load which equals to $1.2 \times$ dead load, plus the ultimate live load and wind load. Universal steel Isections are used for columns and a couple of shear walls are located at the y-direction of the structural boundary to resist the lateral forces in $y$-direction while the proposed system with dampers is used to resist the lateral forces in x-direction as shown in Figure 11. Nonlinear static analyses of the model structures designed without and with ring spring dampers at the ground of the structure are carried out to evaluate the lateral performance of the structure. Microstran software [12] is used for the nonlinear analysis of the model structure. Figure 12, 
displays the distribution along the height of the frames including the location of the control system. The effect of lateral load on the structure was considered as wind load distributed on the height of the structure according to Australian and New Zealand standards which are adopted in this study. Wind velocity was $V=45 \mathrm{~m} / \mathrm{sec}$, total pressure was $P=1.0 \mathrm{kPa}$, and the wind external and internal coefficients were equal to 0.7 and 0.3 respectively. $V_{\text {site }}$ is to be calculated from:

$$
V_{\text {site }}=V_{R} \cdot M_{d}\left(M_{z, c a t} \cdot M_{s} \cdot M_{t}\right)
$$

where $V_{R}=$ regional 3 second gust wind speed, in $\mathrm{m} / \mathrm{s}, M_{d}=$ wind directional multipliers, $M_{z, c a t}=$ terrain height multiplier, $M_{s}=$ shielding multiplier, and $M_{t}=$ topographic multiplier.

(a)

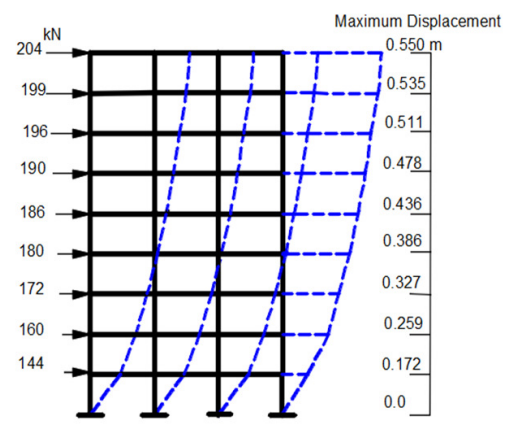

(b)

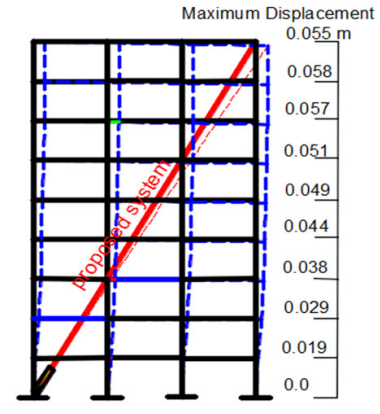

Fig. 12. Displacement of the structure (a) without control system, (b) with control system

The design wind pressure $(P)$ in $\mathrm{Pa}$, is determined for the structure as follows:

$$
P=\left(0.5 \rho_{\text {air }}\right)\left[V_{\text {des }, \theta}\right]^{2} . C_{\text {fig }} \cdot C_{d y n}
$$

where $\rho_{\text {air }}=$ density of air, which is taken equal to $1.2 \mathrm{~kg} / \mathrm{m}^{3}$, $V_{\text {des }, \theta}=$ building orthogonal design wind speed, $C_{f i g}=$ aerodynamic shape factor, and $C_{d y n}=$ dynamic response factor.

The influence of the lateral forces is concentrated at the floor level and the values are distributed through the height of the structure as shown in Figure 12. It can be seen that the maximum displacement at the top of the structure without the control system is $550 \mathrm{~mm}$, which is reduced to $55 \mathrm{~mm}$ after adding the damping system. The percentage of the reduction was about $90 \%$ of the response of the structure. It should be mentioned that using the proposed supplemental system significantly reduces the displacement and inter-story drift of the structure by adding damping. No increases in the floor acceleration of the structure occurred, which is a real benefit of using ring spring dampers opposed to adding conventional diagonal bracings to the frame structure.

\section{CONCLUSION}

This paper describes an alternative system for EBFs in reducing the response of structures under lateral forces. In EBFs, forces are transferred to the brace members through bending and shear forces developed in the ductile steel link. The link is designed to act as a fuse by yielding and dissipating energy while preventing buckling of the brace members. This study is focused on the validation of the effectiveness of using a damping system for lateral resistance of structures. The proposed damping system offers advantages such as: a) the ability to accommodate openings, b) minimal added weight to the structure, and c) the steel system has been constructed with minimum disruption to the function of the building. The main feature of the concept which is adopted in this research is using only one damper on one side or two dampers, one on each side of the structure, to produce the control forces needed, and transfer them to the rest of the building by using tendons. With the proposed system, it is not necessary to distribute dampers throughout the height of the structure. The connection details between the damping system and the floor concrete slab for the transfer of horizontal damping components to the building are described. In order to assess the behavior of the damping system in multi-story buildings, the model of a nine-story frame with and without the system, was created in Microstran and analyzed under lateral loads. The structure behavior was evaluated and the results indicated that the lateral displacements of the multi-story building have been significantly reduced by the installation of this energy absorber and considerable energy has been dissipated by the damping system.

\section{ACKNOWLEDGEMENT}

This research was funded by the Deanship of Scientific Research at Hail University, Hail, Saudi Arabia, under the contract No.160536. Author wishes to express his deep gratitude to the Deanship of Scientific Research and the College of Engineering at Hail University for providing the necessary support for conducting this research.

\section{REFERENCES}

[1] AS/NZS 1170.2:2002, Structural Design Actions: Part 2: Wind Actions, Standards Australia/Standards New Zealand, 2002

[2] E. P. Popov, M. D. Engelhardt, "Seismic eccentrically braced frames", Journal of Construction Steel Research, Vol. 10, pp. 321-354, 1988

[3] M. Badalassi, A. Braconi, S. Caprili, W. Salvatore, "Influence of steel mechanical properties on EBF seismic behavior", Bulletin Earthquake Engineering, Vol. 11, No. 6, pp. 2249-2285, 2013

[4] M. Bosco, P. P. Rossi, "A design procedure for dual eccentrically braced system: Analytical formulation", Journal of Constructional Steel Research, Vol. 80, pp. 440-452, 2013

[5] H. S. Monir, K. Zeynali, "A modified friction damper for diagonal bracing of structures", Journal of Constructional Steel Research, Vol. 87, pp. 17-30, 2013

[6] J. J. G. Ramsay, A. Fussell, R. G. Wilkinson, "Design of ReplaceableLink Eccentric Braced Frames in Post-Earthquake Christchurch", Steel 
Innovations Conference, Christchurch, New Zealand, February 21-22, 2013

[7] S. Momenzadeh, J. Shen, "Seismic demand on columns in special concentrically braced frames", Engineering Structures, Vol. 168, pp. 93107,2018

[8] HERA Report No. R4-150:2017, The Seismic Performance of Structural Steel Building in the Kaikoura Earthquake, HERA, 2016

[9] J. Tait, J. Finnegan, G. Sidwell, "A Low Damage Design Solution for a 15 Storey Steel Framed Building”, New Zealand Society for Earthquake Engineering, Technical Conference and AGM, Wellington, New Zealand, April 26-28, 2013

[10] S. Kravanja, G. Turkalj, S. Silih, T. Zula, "Optimal design of singlestory steel building structures based on parametric MINLP optimization", Journal of Constructional Steel Research, Vol. 81, pp. 86103,2013

[11] C. Adin, J. V. Praveen, R. M. Raveesh, "Dynamic analysis of industrial steel structure by using bracing and dampers under wind load and earthquake load", International Journal of Engineering Research \& Technology, Vol. 5, No. 7, 2016

[12] https://www.civilax.com/microstran-2013-v8-11-130807/

[13] S. K. Azad, C. Topkaya, "A view of research on steel eccentrically braced frame", Journal of Constructional Steel Research, Vol. 128, pp. 53-73, 2017

[14] R. Sabelli, S. Mahin, C. Chang, "Seismic demands on steel braced frame buildings with buckling-restrained braces", Engineering Structures, Vol. 25, No. 5, pp. 655-666, 2003

[15] J. Kim, S. Kim, "Performance-based seismic design of staggered truss frames with friction dampers", Thin-Walled Structures, Vol. 111, pp. 197-209, 2017

[16] A. Chesoan, A. Stratan, D. Dubina, "Design implementation of recentering dual eccentrically braced frames with removal links", Soil Dynamics and Earthquake Engineering, Vol. 112, pp. 174-184, 2018

[17] S. Mirzabagheri, M. Sanati, A. A. Aghakouchak, S. E. Khadem, "Experimental and numerical investigation of rotational friction dampers with multi units in steel frames subjected to lateral excitation", Archives of Civil and Mechanical Engineering, Vol. 15, pp. 479-491, 2015

[18] J. Shen, O. Seker, B. Akbad, P. Seker, S. Momenzadeh, M. Faytarouni, "Seismic performance of concentrically braced frames with and without brace buckling”, Engineering Structures, Vol. 141, pp. 461-481, 2017

[19] J. Ruiz-Garcia, E. Bojorquez, E. Corona, "Seismic behavior of steel eccentrically braced frames under soft-soil seismic sequence", Soil Dynamics and Earthquake Engineering, Vol. 115, pp. 119-128, 2018

[20] G. Ince, H. H. Ince, C. Ocal, "Seismic behavior of RC frames retrofitted by eccentrically braced frames with vertical link", International Journal of Advances in Mechanical and Civil Engineering, Vol. 2, No. 4, 2015

[21] P. H. Sarjou, N. Shabakhty, "Effect of the improved pall friction damper on the seismic response of steel frames", Engineering, Technology \& Applied Science Research, Vol. 7, No. 4, pp. 1833-1837, 2017

[22] G. Xu, M. Yamanari, "Performance of steel frame with linkage system under earthquake excitation", Engineering, Technology \& Applied Science Research, Vol. 9, No. 1, pp. 3796-3802, 2019 